\title{
Investigation of tribological properties of sheet metalfluoroplastic materials
}

\author{
V.N. Kornopoltsev, D. M. Mognonov, O.Zh. Ayurova, M.S. Dashitsyrenova ${ }^{\dagger}$, A. K. Subanakov \\ †mara8106@yandex.ru
}

Baikal Institute of Nature Management Siberian Branch of RAS, 4 Sakhyanovoy str., Ulan-Ude, 670047, Russia

\begin{abstract}
The paper presents the results of tribotechnical tests, thermogravimetric, infrared and x-ray phase analyses of wear products of sheet metalfluoroplastic material with lead (SMFM-Pb) in friction with hardened steel at high slip velocities. Tribotechnical tests show that wear reduction during operation without lubrication in such a regime is provided by the presence of a large volume of the PTFE-composition in the working layer. Moreover, the Charpy rule for friction of SMFM-Pb with the minimum wear rate is completely observed when the component of solid inclusions (in this case of a bronze frame) on the friction surface is one order of magnitude less than the softer and more shear-tolerant PTFE composition surrounding it, the composition being the main donor in the process of the intermediate antifriction layer formation. Based on the infrared and x-ray analyses of wear products of SMFM-Pb, it can be said that the intermediate layer and the layers on the friction surfaces of sheet metalfluoroplastic material with lead and counterbody have an inhomogeneous composition and consist of organofluorine compounds, serving as a lubricant, including a mixture of lead oxyfluorides, fluorides and oxides. Pure PTFE is predominantly transferred to the counterbody that is confirmed by the halo and reflex characteristic of the amorphous and crystalline phases of a polymer. In combination with the PTFE layer transferred to the surface of the counterbody and consisting of highly oriented lamellas with a high bearing capacity and due to the high surface hardness of the counterbody, the resulting third body provides an increase of $p V$-factor at the maximum allowable temperature of $500-520 \mathrm{~K}$ up to $5 \mathrm{MPa} \times \mathrm{m} / \mathrm{c}$ in the new SMFM-Pb.
\end{abstract}

Keywords: polytetrafluoroethylene, sheet metalfluoroplastic material, composite material, friction, wear.

УДК: $62-419.5$

\section{Исследование триботехнических свойств листовых металлофторопластовых материалов}

\author{
Корнопольцев В.Н., Могнонов Д. М., Аюрова О.Ж., Дашицыренова М. С. ${ }^{\dagger}$, \\ Субанаков А.К. \\ Байкальский институт природопользования СО РАН, ул. Сахьяновой 4, Улан-Удэ, 670047, Россия
}

В работе представлены результаты триботехнических испытаний, термогравиметрического, инфракрасного и рентгенофазового анализа продуктов изнашивания листового металлофторопластового материала со свинцом (ЛМФМ-Рb) при трении с высокими скоростями скольжения по упрочненной стали. Триботехнические испытания показывают, что уменьшение износа при работе без смазки в таком режиме обеспечивается наличием в рабочем слое большой объемной составляющей политетрафторэтиленовой (ПТФЭ)-композиции. Причем, правило Шарпи для трения ЛМФМ-Рb с минимальной интенсивностью износа в полной мере соблюдается тогда, когда составляющая твердых включений на поверхности трения, в данном случае бронзового каркаса, на порядок меньше более мягкой и податливой при сдвиге окружающей его ПТФЭ-композиции, которая является главным донором в процессе образования промежуточного антифрикционного слоя. На основании ИК- и рентгенофазового анализа продуктов изнашивания ЛМФМ-Рb можно констатировать, что промежуточный слой и слои на поверхностях трения листового металлофторопластового материала со свинцом и контртела имеют неоднородный состав и состоят из фторорганических соединений, выполняющих роль смазки, с включением смеси оксифторидов, фторидов и оксидов свинца. На контртело преимущественно переносится чистый ПТФЭ, что подтверждается наличием гало и рефлекса, характерных для аморфной и кристаллической фаз полимера. В сочетании с перенесенным на поверхность контртела слоем ПТФЭ в виде высокоориентированных ламелей, обладающих значительной несущей способностью, а также высокой поверхностной твердостью контртела, образующееся третье тело обеспечивает новому ЛМФМ-РЬ увеличение фактора $p V$ при предельно допустимой температуре 500 - $520 \mathrm{~K}$ до $5 \mathrm{MПа} \times \mathrm{M} / \mathrm{c}$.

Ключевые слова: политетрафторэтилен, листовой металлофторопластовый материал, композиционный материал, трение, износ. 


\section{1. Введение}

Создание универсальной безызносной пары трения, способной длительно работать в различных климатических условиях без применения жидких смазочных материалов, является актуальной задачей триботехнического материаловедения. Передовым решением в данном направлении является разработка самосмазывающихся материалов путем создания на стальной подложке пористого бронзового слоя толщиной в допустимый износ [1-5]. При этом возможно получить слой самого разнообразного состава с последующей пропиткой его смазочным материалом или полимером. Такие материалы широко выпускаются промышленностью в виде лент. Заполнение пор бронзового слоя композициями на основе политетрафторэтилена (ПТФЭ) с различными наполнителями позволяет создавать материалы, способные работать без смазки в широком диапазоне температур (от 73 до 553 К) при высоких давлениях (> 100 МПа). Однако долговечность подшипников из таких материалов значительно снижается при повышении скорости скольжения, кроме того, существующие конструкции листовых металлофторопластовых материалов (ЛМФМ) имеют неравномерный коэффициент трения по мере изнашивания рабочего слоя на допустимую глубину.

Установлено [6], что длительную работу ЛМФМ при трении без смазочного материала с фактором $p V$ выше $1 \mathrm{MПа \times м/с} \mathrm{можно} \mathrm{обеспечить} \mathrm{только} \mathrm{наличием}$ в рабочем слое высокой объемной доли ПТФЭ-композиции, которая является основным источником образования антифрикционного слоя. Правило Шарпи для ЛМФМ в полной мере соблюдается тогда, когда содержание твердых включений на поверхности трения (в данном случае бронзового каркаса) на порядок меньше содержания более мягкой и податливой окружающей их ПТФЭ-композиции. На основании проведенных исследований разработан способ получения ЛМФМ, который позволяет регулировать $p V$-фактор материалов [7]. Так при испытаниях $[6,8]$ установлено, что длительную работу ЛМФМ, содержащих в бронзовом каркасе рабочего слоя композицию ПТФЭ со свинцом в полной мере обеспечивает образующееся новое химическое соединение, обладающее иными физико-механическими свойствами, чем материалы рабочего слоя.

В связи с этим работа посвящена изучению продуктов изнашивания листового металлофторопластового материала, содержащего свинец, при трении по упрочненной стали при высоких скоростях скольжения.

\section{2. Методика исследований}

Способ получения ЛМФМ-Рb подробно описан в работе [7]. В качестве стальной основы использовали низкоуглеродистую сталь толщиной 1 мм. Для создания пористой структуры применяли смесь стандартных высокодисперсных порошков меди и олова. Свободное пространство пористого слоя заполняли прямым прессованием композиционной порошковой шихтой на основе политетрафторэтилена марки ПН и свинца $(\mathrm{Pb})$ марки ПСА в соотношении компонентов 35 и 65 мас.\%, с последующей термообработкой при 640 - 650 К [9].

Трибоиспытания проводили на воздухе по схеме «вращающийся вал - неподвижный частичный вкладыш» на машине трения СМТ-1 ( $p=1$ МПа, $V=3$ м/с). В качестве контртела использовали втулку из стали 45 с диффузионно-борированным покрытием: $d_{\text {вн }}: d_{\text {н }}=22: 38$ мм, $b=35$ м $\left(d_{\text {вн }}-\right.$ внутренний диаметр, $d_{\text {н }}-$ наружный диаметр, $b$ - ширина), $R_{a} \approx 0.63$ мкм, толщина диффузионного слоя $\approx 250$ мкм, $H V=19000-19500$ МПа. Графические зависимости температуры и износа строили по среднеарифметическим значениям при испытаниях трех образцов. Время непрерывной работы машины при длительных испытаниях - 7 - 10 ч. Общая длительность работы машины для одного образца составляла 60-100 часов. При кратковременных испытаниях показания снимали на второй-третий час работы при установившихся параметрах трения с последующим увеличением нагрузки. Линейный износ определяли микрометром МТ как разность толщин вкладыша после 7-10 часов испытания. Температуру трения определяли хромель-копелевой термопарой с обратной стороны образца ЛМФМ-Pb и фиксировали миллиамперметром Ш4500.

ИК-спектры продуктов изнашивания регистрировали на ИК-Фурье-спектрометре Excalibur HE 3100 в области длин волн 4000-600 см${ }^{-1}$ с использованием приставки нарушенного полного внутреннего отражения (HПВО), кристалл ZnSe с алмазным напылением (Varian, США).

Для термогравиметрического анализа образцов использовали синхронный термический анализатор STA 449 C Jupiter фирмы NETZSCH (Германия), скорость нагрева $5 \%$ мин.

Рентгенофазовый анализ проводили на дифрактометре D8 Advance Bruker AXS, $\mathrm{Cu}_{\mathrm{Ka}}$-излучение (Германия).

Для изучения поверхности поперечных срезов ЛМФМ-РЬ и контртела использовали металлографический микроскоп МИМ-1600Б (Россия).

\section{3. Результаты исследования и их обсуждение}

Ранее установлено [7], что причиной роста температуры в зоне трения при повышении скорости скольжения является большое содержание бронзы в пористом рабочем слое ЛМФМ, которое для промышленных ленточных материалов составляет 70 - 75 об.\%. Столь высокое содержание определяется способом получения ленточных материалов, в котором слой получают насыпанием сферического порошка на движущуюся ленту и его спеканием. В результате образуется только одна структура пористого слоя.

На Рис. 1 приведена графическая зависимость степени заполнения рабочего слоя бронзовых каркасов ЛМФМ в зависимости от толщины слоя, полученного с применением сетки в сравнении с промышленным материалом марки DU (металлофторопластовый материал фирмы «Glacier»). Вычисление площади бронзового каркаса проводилось стандартным методом развертки продольных шлифов хордами.

Видно, что относительная площадь сетчатого каркаса меньше, чем у промышленного аналога, что и определя- 


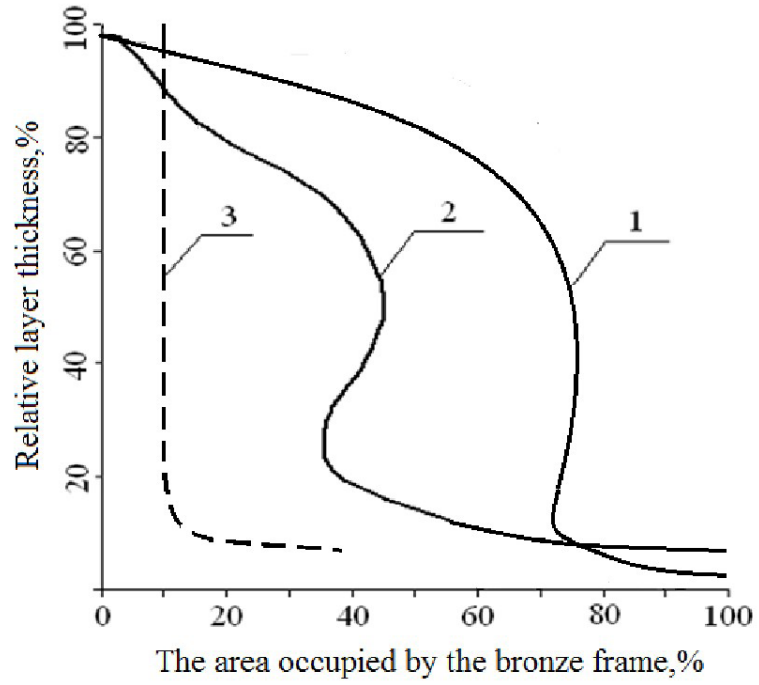

Рис. 1. Относительная площадь, занимаемая бронзой на поверхности по глубине рабочего слоя ЛМФМ: 1 - материал марки DU, 2 - припеченная сетка, 3 - отвечающая правилу Шарпи.

Fig. 1. Relative area occupied by bronze on the surface along the depth of the working layer of LMWM: 1 - material of the brand DU, 2 - baked mesh, 3 - corresponding to the Charpy rule.

ет увеличение износостойкости [6]. Однако в обоих случаях выражена неравномерность предполагаемого пятна контакта бронзового слоя с контртелом. Это нарушает стабильность триботехнических параметров по мере изнашивания слоя на допустимую глубину.

Полученные результаты приводят к выводу, что для сохранения смазочной способности рабочего слоя и стабильности коэффициента трения необходимо технологическое решение, обеспечивающее получение пористого каркаса со структурой, отвечающей кривой 3 на Рис. 1.

Создание рельефа пористого слоя во время припекания порошка к ленте не рассматривалось ни в одной работе, возможно из-за трудности осуществления процесса. Нами предложен способ получения ЛМФМ кассетным методом $[10,11]$. В результате получен ЛМФМ-Pb [8], имеющий столбчатую структуру пористого слоя (Рис. 2). В зависимости от рисунка рифленой поверхности, при помощи которого создается каркас слоя, можно регулировать объем свободного простран- ства пористого слоя, содержащего антифрикционную ПТФЭ-композицию. Для триботехнических испытаний использовали ЛМФМ-Pb (Рис. 2), у которого объемная доля бронзового каркаса по мере изнашивания составляет около 15 об.\%.

Длительные сравнительные испытания [9] нового ЛМФМ-Рb показали, что он имеет значительное отличие по износостойкости и параметрам изменения температуры трения в сравнении с промышленными аналогами DU и ЛМФМ с пористым слоем из сетки. Износ основного рабочего слоя для нового материала в режиме трения при факторе $p V=3 \mathrm{MПа} \times \mathrm{m} / \mathrm{c}$ за 100 часов испытания составлял менее 15 мкм. Температура с обратной стороны вкладыша имела более низкие и стабильные значения, не превышающие 440 К. Главным фактором стабильного трения является образующееся третье тело между сопряженными поверхностями $[12,13]$, имеющее ярко выраженный желтый цвет. Это явление отмечали еще Митчелл и Пратт при испытаниях ЛМФМ с композицией ПТФЭ и свинца в рабочем слое [1].

Кратковременные трибоиспытания показали, что кривые зависимостей коэффициентов трения от нагрузки имеют минимумы. Увеличение можно связать только с переходом условий трения сопряженных поверхностей от упругой деформации к пластической, о чем свидетельствует исчезновение желтого налета на трущихся поверхностях, т.е. образующееся промежуточное вещество, выполняющее роль псевдожидкой смазки, выносится из зоны трения.

Термогравиметрические исследования продуктов изнашивания желтого цвета показывают, что 10\% потери массы образца происходят при 513-523 К. ИК-спектры продуктов изнашивания, собранных с поверхности контртела, наряду с интенсивными пиками, соответствующими валентным колебаниям групп $\mathrm{CF}_{2}$ (1208 и $1152 \mathrm{~cm}^{-1}$ ), содержат новую размытую область пиков, смещенных в область $1480-1300 \mathrm{~cm}^{-1}$, характерных для колебаний С-О в образующихся при трении перфторкарбоксилатных солях [14-18]. Это дает основание полагать, что происходят изменения молекулярной структуры ПТФЭ с образованием перфторкарбоновых кислот, которые при взаимодействии со свинцом образуют соли $\mathrm{Pb}\left(\mathrm{R}_{\mathrm{f}}-\mathrm{COO}\right)_{2}$. Сопоставив эти данные с графиком (Рис. 3) можно утверждать, что повышение коэффициента трения связано с тем, что образующееся фторорганическое соединение, входящее в состав про-

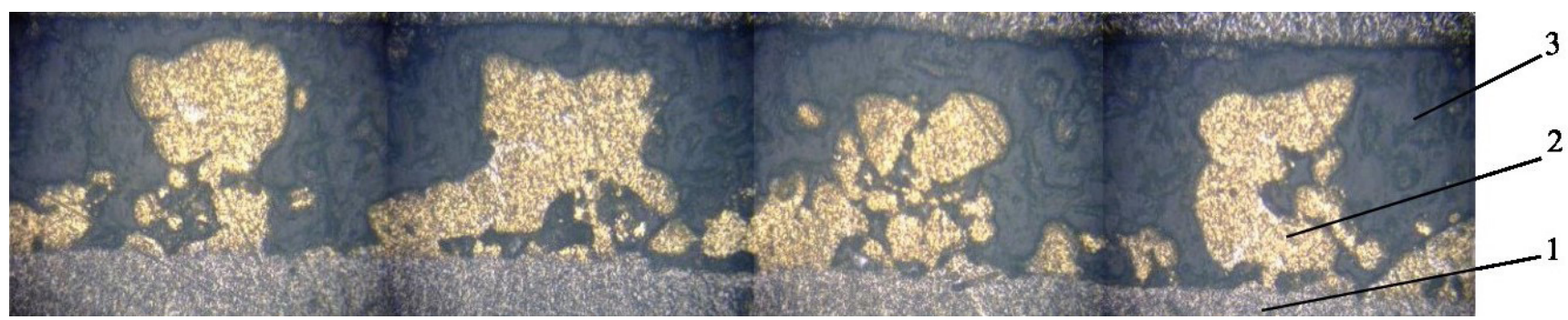

Рис. 2. Микрофотография поперечного разреза ЛМФМ-Рb с пористым бронзовым слоем, имеющим «столбчатую» структуру: 1 - стальная основа, 2 - шип припеченного слоя бронзы, 3 - ПТФЭ-композиция.

Fig. 2. A microphotograph of a cross-section of SMFM-Pb with a porous bronze layer having a "columnar" structure: 1 - steel base, 2 - spike of the bronze layer, 3 - PTFE-composition. 


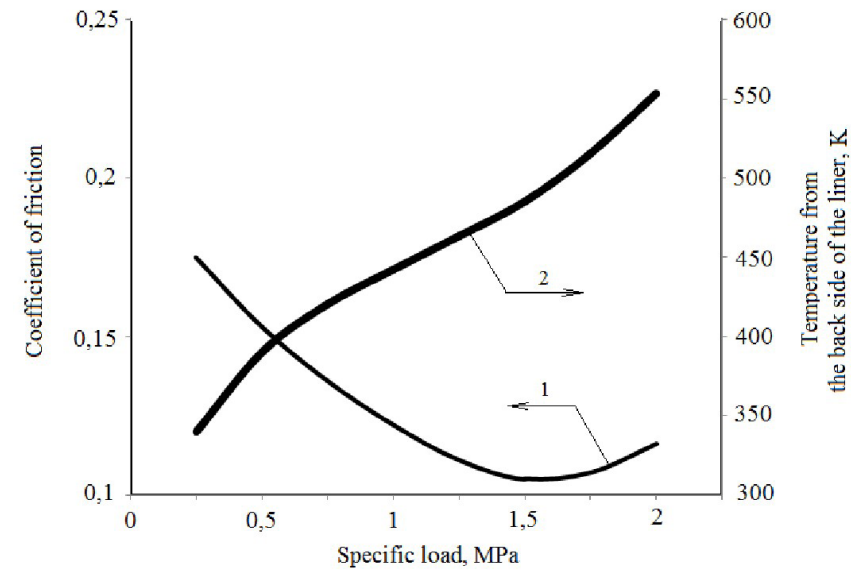

Рис. 3. Графическая зависимость температуры и коэффициента трения от нагрузки при трении ЛМФМ по упрочненной стальной поверхности $(V=3 \mathrm{~m} / \mathrm{c}) .1$ - коэффициент трения, 2 - температура с обратной стороны образца.

Fig. 3. Graphic dependence of temperature and friction coefficient on the load during friction of SMFM on hardened steel surface $(V=3 \mathrm{~m} / \mathrm{s}) .1$ - coefficient of friction, 2 - temperature from the back of the sample. межуточного тела, обладает вязкотекучими свойствами в разогретом состоянии, и выносится из зоны трения при температуре выше $523 \mathrm{~K}$.

Так, при трибоиспытаниях показано, что после снятия горячего образца с машины трения на его поверхности желтый слой обладает вязкотекучими свойствами, а после охлаждения - становится твердым. Этим обусловлен высокий пусковой коэффициент трения, достигающий значения $0.23-0.25$. Только после разогрева системы коэффициент трения снижается до минимального значения.

РФА показал большое содержание оксифторидов, фторидов и оксидов свинца $[19,20]$, чем и определяется ярко выраженный желтый цвет продуктов износа. В продуктах массопереноса, собранных с поверхности трения контртела (Рис. 4.1), самый интенсивный пик наблюдается для ПТФЭ. Во всех случаях можно отметить гало, характерное для аморфной фазы полимера в области $2 \theta 33-35^{\circ}$.

При исследовании поверхности трения контртела оптическим методом наблюдается рисунок из тонких прозрачных лент, наложенных друг на друга, возможно, обусловленный высокоориентированными ламелями ПТФЭ. Учитывая, что тонкие пленки полимера имеют предел прочности на сжатие, сравнимый с металлами, можно объяснить отсутствие контактного схватывания металлов каркаса ЛМФМ-Pb и контртела при повышенных нагрузочно-скоростных параметрах трения.

В продуктах изнашивания, вытесненных из зоны трения (Рис. 4.2), наблюдается незначительное количество фторорганических соединений. Выносимая пыль состоит из смеси оксифторидов, фторидов и оксидов свинца, что согласуется с простым механическим переносом частиц, не обладающих высокой активностью и антифрикционными свойствами. Состав слоя на поверхности трения листового материала может свидетельствовать о переносе композиции свинца и ПТФЭ, вырываемых их рабочего слоя ЛМФМ-Рb небольшими фрагментами.

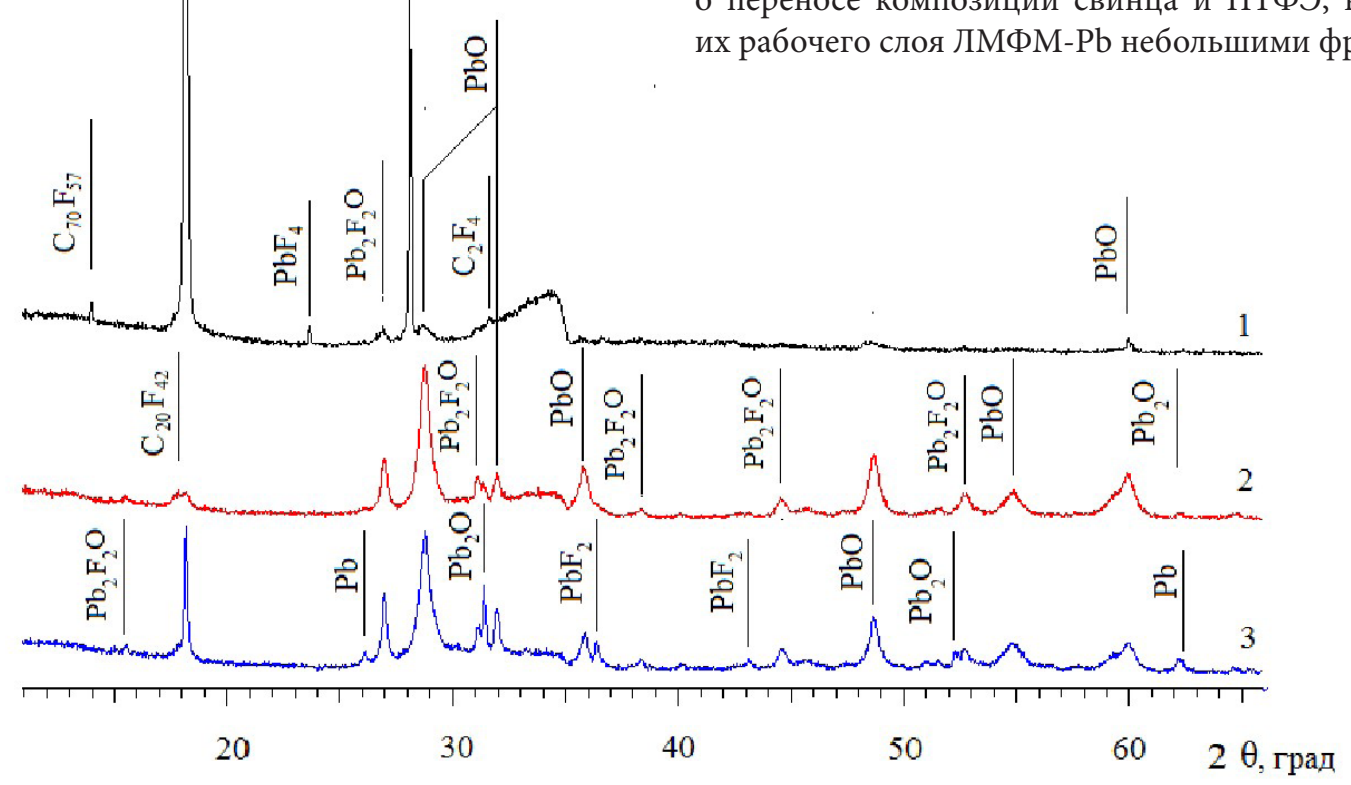

Рис. 4. Дифрактограммы продуктов изнашивания: 1 - собранных с поверхности контртела; 2 - выносимых из зоны трения; 3 - собранных с поверхности трения ЛМФМ.

Fig. 4. Diffractograms of wear products: 1 - collected from the surface of the counter-body; $2-$ taken out of the friction zone; 3 - collected from the friction surface of SMFM. 


\section{4. Заключение}

Результаты исследования процессов трения в представленной конструкции листового металлофторопластового материала со свинцом при работе в паре с контртелом из углеродистой стали с упроченной поверхностью показали, что продукты изнашивания, состоят из фторорганических соединений, выполняющих роль смазки, с включением смеси оксифторидов, фторидов и оксидов свинца.

При трении нового листового металлофторопластового материала со свинцом по контртелу с высокой поверхностной твердостью образуется третье тело, которое в сочетании с высокоориентированными ламелями политетрафторэтилена, обеспечивает увеличение фактора $p V$ при предельно допустимой температуре $500-520 \mathrm{~K}$ до $5 \mathrm{M \Pi а} \times \mathrm{M} / \mathrm{c}$.

\section{Литература/References}

1. D.C. Mitchell, G. Pratt. Friction, wear and physical of some filled P.T. F. E. bearing materials: Proc. Conf. on lubrication and wear. London (1957) P. 416.

2. E. R. Braithwaite. Solid Lubricants and Surfaces. London, Oxford: Pergamon press (1964) 286 p.

3. A.P. Semenov, Yu. V. Savinskiy. Metalloftoroplastovyie podshipniki. Moscow, Mashinostroenie (1976) 192 p. (in Russian) [А.П. Семенов, Ю.В. Савинский. Металлофторопластовые подшипники. Москва, Машиностроение (1976) 192 с.]

4. C.A. Byichkov, I.G. Lavrenko, O. Yu. Nechiporenko, I. M. Romashko, S.D. Mladinov. Open Information and Computer Integrated Technologies. 59, 343 (2013). (in Ukrainian) [С. А. Бычков, И.Г. Лавренко, О. Ю. Нечипоренко, И. М. Ромашко, С. Д. Младинов. Открытые информационные и компьютерные интегрированные технологии. 59, 343 (2013).]

5. C.A. Byichkov, I.G. Lavrenko, O.Yu. Nechiporenko, I.M. Romashko, S.D. Mladinov. Sostoyanie voprosa perspektivy primeneniya MFL novykh proizvoditelei v uzlakh treniya samoletov: Materialy IV tehnicheskoy konferentsii Ukrainskogo otdeleniya SAMPE. Ukraine (2014) Р. 9. (in Ukrainian) [С. А. Бычков, И. Г. Лавренко, О.Ю. Нечипоренко, И. М. Ромашко, С.Д. Младинов. Состояние вопроса и перспективы применения МФЛ новых производителей в узлах трения самолетов: Материалы IV технической конференции Украинского отделения SAMPE. Украина, Киев (2014) С. 9.]

6. V.N. Kornopoltsev, N. V. Kornopoltsev, D. M. Mognonov. J. Friction and wear. 30(4), 281 (2009). (in Russian) [B.Н. Корнопольцев, Н.В. Корнопольцев, Д. М. Могнонов. Трение и износ. 30(4), 385 (2009).]

7. V.N. Kornopoltsev. Patent RF № 2438829, IPC B22F7/04, F16C33/12, (2012). (in Russian) [B.Н. Корнопольцев. Патент РФ №2438829, МПК B22F7/04, F16C33/12, (2012).]
8. V. N. Kornopoltsev. J. Friction and wear. 31(5), 359 (2010). (in Russian) [В.Н. Корнопольцев. Трение и износ. 31(5), 479 (2010).]

9. V.N. Kornopoltsev, N. V. Kornopoltsev, D. M. Mognonov, I. A. Farion. J. Chemistry for Sustainable Development. 13, 757 (2005). (in Russian) [B.Н. Корнопольцев, Н. В. Корнопольцев, Д. М. Могнонов, И.А. Фарион. Химия в интересах устойчивого развития. 13, 757 (2005).]

10. V. N. Kornopoltsev. Patent RF № 2602217: IPC C23C8/70, (2016). (in Russian) [В.Н. Корнопольцев. Патент РФ № 2602217, МПК С23 С8/70, (2016).]

11. N. V. Kornopoltsev. Patent RF№ 1418999. B22F7/04, (1993). (in Russian) [Н. В. Корнопольцев. Патент РФ № 1418999, B22F7/04, (1993).]

12. Ed. by Yu-Ving May, Zhong-Zhen Yu. Polimernyie nanokompozityi. Moscow, Tehnosfera (2011) 688 p. (in Russian) [Под ред. Ю-Винг Май, ЖонгЖен Ю. Полимерные нанокомпозиты. Москва, Техносфера (2011) 688 c.]

13. A. V. Anisimov, V.E. Bahareva, I. V. Nikitina, A. S. Savelov. Voprosy Materialovedeniya. 3(91), 83 (2017). (in Russian) [А.В. Анисимов, В.Е. Бахарева, И.В. Никитина, А.С. Савелов. Вопросы материаловедения. 3(91), 83 (2017).]

14. K. Nakamoto. IR spectra and Raman spectra of inorganic and coordination compounds. Moscow, Mir (1991) 336 p. (in Russian) [К. Накамото. ИК-спектры и спектры КР неорганических и координационных соединений. Москва, Мир (1991) 336 с.]

15. E. Prech, F. Byulmann, K. Affolter. Determination of the structure of organic compounds. Tables of spectral data. Moscow, Binom (2006) 438 p. (in Russian) [Э. Преч, Ф. Бюльманн, К. Аффольтер. Определение строения органических соединений. Таблицы спектральных данных. Москва, Бином (2006) 438 с.]

16. K. Nakanisi. Infrakrasnyie spektryi i stroenie organicheskih soedineniy. Moscow, Mir (1965) 216 p. (in Russian) [К. Наканиси. Инфракрасные спектры и строение органических соединений. Москва, Мир (1965) 216 c.]

17. M. A. Sidebottom, A. A. Pitenis, C. P. Junk, D. J. Kasprzak, G.S. Blackman, H.E. Burch et al. Wear. 362-363, 179 (2016).

18. K. L. Harris, A. A. Pitenis, W. G. Sawyer et. al. Macromol. 48, 3739 (2015).

19. Yu.K. Mashkov. Tribologiya konstruktsionnyih materialov. Omsk, OmGTU (1996) 304 p. (in Russian) [Ю.К. Машков. Трибология конструкционных материалов. Омск, ОмГТУ (1996) 304 с.]

20. N.P. Istomin, A.P. Semenov. Antifriktsionnyie svoystva kompozitsionnyih materialov na osnove ftorpolimerov. Moscow, Nauka (1981) 147 p. (in Russian) [Н.П. Истомин, А.П. Семенов. Антифрикционные свойства композиционных материалов на основе фторполимеров. Москва, Наука (1981) 147 с.] 